J. Lake Sci.(湖泊科学) , 2008, 20(1): 65-75

http://www.jlakes.org. E-mail: jlakes@niglas.ac.cn

(C2008 by Journal of Lake Sciences

\title{
临夏盆地新生代沉积物粒度记录与亚洲内陆干旱化*
}

\author{
徐先海 ${ }^{1,3}$, 方小敏 ${ }^{2,3}$, 宋春晖 ${ }^{3}$, 范马洁 ${ }^{3}$, 沈 吉 $^{4}$ \\ (1: 安徽省安庆师范学院资源环境系, 安庆 246011) \\ (2: 中国科学院青藏高原研究所, 北京 100085) \\ (3: 兰州大学西部环境教育部重点实验室 \&兰州大学地理系, 兰州 730000) \\ (4: 中国科学院南京地理与湖泊研究所, 南京 210008)
}

摘 要: 临夏盆地毛沟剖面高分辨率粒度记录研究表明, 29-7.4Ma 间, 临夏盆地的古气候一直保持相对稳定，而其中短暂的 沉积相的改变是盆地对该期间青藏高原构造隆升事件的响应; 从 7.4Ma 开始, 流域外的风尘物质开始逐步被带人盆地, 并经 过了 6.4 Ma 和 5.3 $\mathrm{Ma}$ 的两次加速过程, 揭示了我国西北内陆干旱气候可能从 7.4 Ma 左右开始, 且在 $6.4 \mathrm{Ma}$ 和 5.3 Ma 左右经过 两次加强.通过与青藏高原构造隆升事件记录和全球气候记录对比, 揭示高原在 9-7Ma 开始的逐步隆升和期后的阶段性加速 隆升以及同期开始的全球变冷, 尤其北极冰盖的形成和扩张可能是亚洲内陆干旱化的重要驱动机制.

关键词: 临夏盆地; 粒度; 干旱化; 高原隆升; 全球变冷

\section{Grain-size records of Cenozoic Lacustrine sediments from Linxia Basin and the aridification of Asian Inland}

\author{
XU Xianhai ${ }^{1,3}$, FANG Xiaomin ${ }^{2,3}$, SONG Chunhui ${ }^{3}$, FAN Majie ${ }^{3} \&$ SHEN Ji ${ }^{4}$ \\ (1: Anqing Teachers' College, Anqing 246011,P.R.China) \\ (2: Institute of Tibetan Plateau Research, CAS, Beijing 100085, P.R.China) \\ (3: Key Laboratory of West China's Environmental Systems(MOE), Lanzhou Universtiy, Lanzhou 730000, P.R.China) \\ (4: Nanjing Institute of Geography and Limnology, CAS, Nanjing 210008, P.R.China)
}

Abstract: High-resolution grain size records from Maogou section in Linxia Basin were characterized with relative stable fluctuation from 29Ma and 7.4 Ma, and changes in several sedimentary facies responded to Tibetan uplift in some short intervals. At about 7.4Ma, aeolian dusts gradually entered into Linxia Basin, and input fluxes of aeolian dusts had two rapid increased phases respectively at about 6.4Ma and 5.3 Ma, suggesting that NW China drying climate began at 7.4 Ma and strengthened rapidly at $6.4 \mathrm{Ma}$ and 5.3Ma. Comparing of our records with the Tibetan uplift and global climatic records, we found that the gradual uplift of the Tibetan Plateau and global cooling, especially the onset of Arctic ice sheet, since about 9-8 Ma, may be the two important forcing mechanisms for the fast aridification of Asian inland.

Keywords: Linxia Basin; grain size; aridification; Tibetan uplift; global cooling

新生代地球上发生了一系列的重大地质事件，导致全球气候环境发生了巨大改变: 全球变冷 ${ }^{[1-2]}$, 北美 和亚洲内陆干旱化 ${ }^{[3]}$, 亚洲季风形成 ${ }^{[4-7]}$ 等. 其中, 干旱化问题是对人类生存环境影响最为深刻和最为广 泛的重大科学问题之一, 其发生和发展过程倍受国际社会的关注. 毫无疑问, 造成全球干旱化加剧的原 因除近代人类活动影响外，自然变化在长期干旱化的形成和演化过程所起的作用不容忽视. 越来越多的 研究表明晚新生代青藏高原的急剧隆起和全球变冷在亚洲内陆干旱化的演变中起着举足轻重的作用 ${ }^{[8-14]}$.

\footnotetext{
* 国家自然科学基金重点基础项目(40334038)资助. 2007-01-08 收稿; 2007-07-18 收修改稿. 徐先海, 男, 1971 年生, 博士; E-mail: xhxu@niglas.ac.cn.
} 

我国北方干旱化是在全球变化的背景下，在自然和人类活动的共同作用下长期演化的结果. 面对西 北内陆干旱化的发展趋势，要解决的关键科学问题是揭示亚洲内陆干旱化的起始时间、演化过程和形成 机理，以探索其发展规律，预测其发展趋势，揭示其与高原隆升和全球变冷的关系. 我国西北地区主要 由大型内陆盆地组成, 盆地中堆积了巨厚的新生代沉积物, 它们详细地记录了我国西北的干旱化过程. 本次研究的临夏盆地毛沟剖面位于甘肃省临夏市, 盆地在 $29-1.7 \mathrm{Ma}$ 间一直处于封闭古湖状态 ${ }^{[15]}$, 以低能 环境细粒沉积物为主, 成岩作用弱, 且基本连续 ${ }^{[16-17]}$, 非常适合进行气候环境研究, 是获取干旱气候环 境记录的理想载体.

本文在国家 “八五” 和 “九五” 攀登计划以及 “973” 国家重点基础研究规划等项目研究的基础上，通 过运用高分辨率粒度气候代用指标的分析，提取盆地沉积物高分辨率气候变化信息，揭示重大气候转型 事件, 反演亚洲内陆干旱化及其与高原隆升和全球变冷的关系.

\section{1 研究区的地质地理概况}

临夏盆地位于青藏高原东北边缘(图 1)，大致沿西北－南东向延伸，海拔一般在 2000-2400m 之间， 属于第三纪大型陇中盆地的西南隅，距兰州市南约 $100 \mathrm{~km}$, 其四周为一系列基岩山地和深断裂带所包围: 西以雷积山东麓逆冲断裂带与青藏高原分界, 南以西秦岭北麓深大断裂相间与甘南高原相毗邻, 北以祁 连山东延余脉马衔山和兰州盆地相隔。从宏观地貌部位上它是青藏高原与黄土高原衔接带上的一个新生

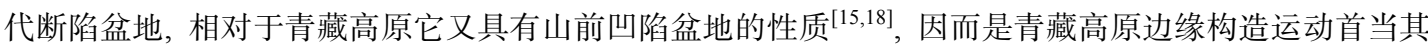
冲的构造波及区，青藏高原的隆升过程对盆地环境的变化有着极为深刻的影响. 黄河从盆地的西北角流 人并流出，其主要支流大夏河和洮河贯穿盆地南北并注人黄河，随着高原的间歇性抬升，河流切穿了盆 地的晚新生代地层, 形成七级阶地, 并于其上堆积了巨厚连续的黄土-古土壤序列 ${ }^{[19-20]}$. 盆地中新生界非 常发育, 大致以大夏河南北向的正断层为界将盆地一份为二, 盆地西部主要位于正断层的下降盘并紧接 青藏高原, 盆地中第三纪红层厚达 1600 多米, 但已强烈变形和禇皱; 盆地东部主要位于正断层的上升盘, 与南侧的西秦岭相连, 构造相对稳定, 第三纪红层在盆地中仅厚约 400-500m, 地层水平, 延伸稳定.红 层之上, 第四系也相当发育, 下部为湖泊沉积, 上部为黄土沉积, 厚约 100-400m 左右. 整个盆地新生代 地层从渐新世至今几乎呈连续沉积, 提供了比南亚西瓦利克群更完整的新生代地层记录, 为较准确的揭 示盆地环境变化分析提供了有利的条件.

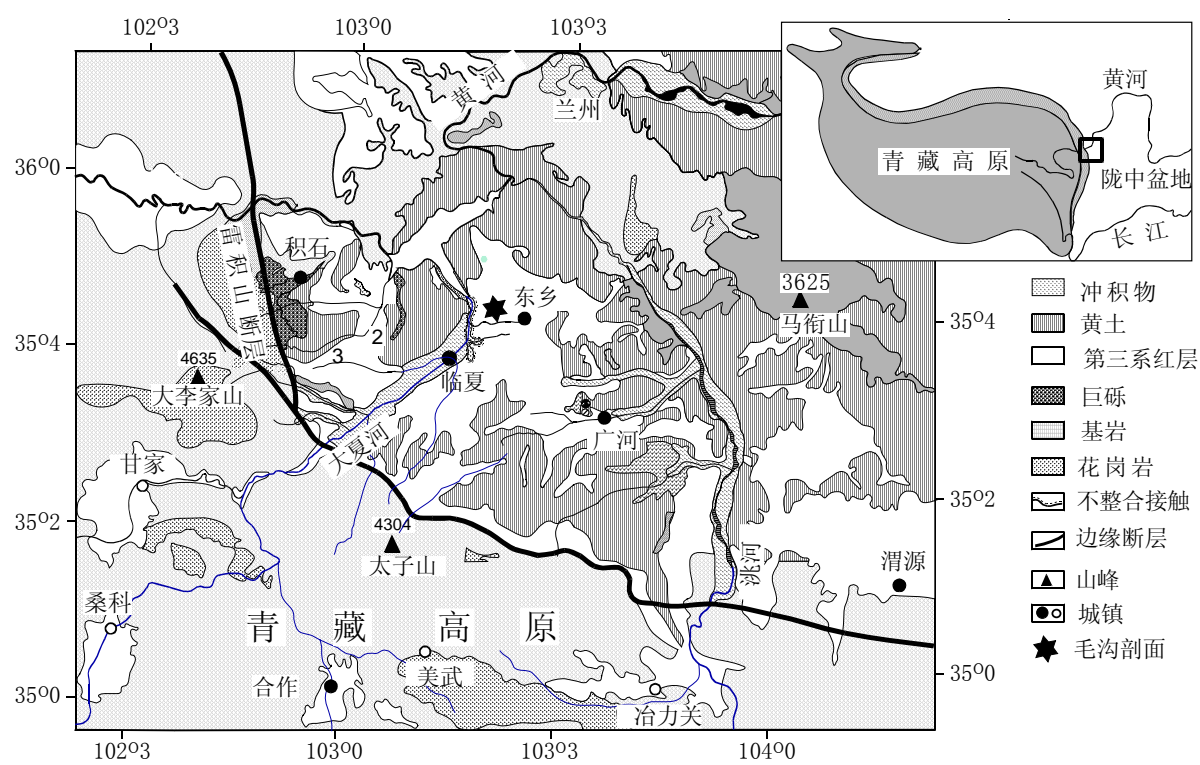

图 1 临夏盆地地质概况 ${ }^{[4]}$

Fig.1 Geological map of Linxia Basin 
在自然地理上，临夏盆地处于东部季风区、西北干旱区及青藏高寒区三大自然带的交汇地带，又恰 好处于季风三角区的顶点部位, 受西风环流和季风环流两大系统的影响, 具有较为典型的大陆性季风气 候特征, 气候温凉、半湿润, 区内 1 月份平均气温为 $0.7-13.4^{\circ} \mathrm{C}, 7$ 月份平均气温 $25.0-12.0^{\circ} \mathrm{C}$, 年降水量 为 $506.3 \mathrm{~mm}^{[21]}$, 除盆地周围山地有温带山地及亚高山针叶林分布外, 盆地内为温带落叶阔叶林-草原景观.

\section{2 样品的采集和测试}

毛沟剖面位于临夏盆地地理中心构造稳定地区，地层总厚度 $443 \mathrm{~m}$ ，由他拉组、中庄组、上庄组、东 乡组、柳树组以及何王家组组成. 剖面岩性变化大致可描述为:

(1)何王家组上段: 褐黄色湖相泥岩含大量䥻结核和石膏, 顶部产大量三趾马、大唇犀等化石.

(2)何王家组下段: 河流砂砾岩, 强烈钙质胶结.

(3)柳树组上段：褐黄色含锈斑湖相粉砂岩, 含大量钻结核, 产四棱齿象等化石.

(4)柳树组下段: 褐黄色块状泥岩, 含钙结核.

(5)东乡组上段: 紫红色泥岩与灰白青灰色泥灰岩交互, 底部含大量三趾马化石.

(6)东乡组下段: 褐黄色钻质胶结粉砂岩、砂岩夹少量泥岩, 底为薄层砂砾岩.

(7)上庄组上段: 褐红色泥岩, 具韵律层理, 含三趾马化石.

(8)上庄组下段: 褐红色河湖相粉砂岩、砂岩.

(9)中庄组上段: 褐红色泥岩, 具韵律层理, 含大量准同生、次生石膏.

(10)中庄组下段: 褐黄色河流相砂岩、砂砾岩夹少量紫红色泥岩，产石膏和象、巨犀类化石.

(11)他拉组上段: 紫红色块状、湖相泥岩.

(12)他拉组中段: 紫红色河湖相粉砂岩和泥岩互层, 强钻质胶结.

(13)他拉组下段: 山区紫红色河流相红色砂砾岩.

为获取原生样品, 我们首先将研究剖面彻底开挖至新鲜层面, 以保证采集样品的可靠性, 以 $10 \mathrm{~cm}$ 等 间距进行高密度连续系统采样，在有粗砂岩和砾岩的地方采样距离适度放宽，同时局部地段加密. 共采 集粒度实测样品 4300 余块, 整个剖面地层由下而上分别划分为他拉组、中庄组、上庄组、东乡组、柳树组 和何王家组，古地磁年龄 ${ }^{[16,18]}$ 分别是 $29-21.4 \mathrm{Ma} 、 21.4-14.68 \mathrm{Ma} 、 14.68-13.07 \mathrm{Ma} 、 13.07-7.8 \mathrm{Ma} 、 7.8-6.25$ Ma 和 6.25-4.48 Ma.

采集的样品绝大多数为粉砂岩和泥岩, 少数为砾岩、砂岩, 胶结疏松, 通过综合对比, 我们对粗粒样 品的测试(直径大于等于 $2 \mathrm{~mm}$ )采用篮析法, 对细粒样品的测试(直径小于 $2 \mathrm{~mm}$ )采用激光粒度仪法.用于篮 析的样品量约为 200-500g, 砾岩样品量加大, 在振篮机上篮 10-15 min, 然后按粒级称重, 精确至 $0.01 \mathrm{~g}$. 对于组成较细的样品, 我们采取激光粒度仪法, 其步骤为: 取一定量的样品放人研铑中, 轻轻研磨以防 止人为增加细颗粒含量, 取研磨后的样品约 $0.2 \mathrm{~g}$, 放人 $100 \mathrm{ml}$ 烧杯中. 先向样品中注人 $10 \mathrm{ml}$ 浓度为 $10 \%$ 的 $\mathrm{H}_{2} \mathrm{O}_{2}$ 溶液以除去其中的有机质，后把样品放到电热板上加热，在加热的过程中不断加人浓度为 $10 \%$ 的 盐酸溶液和蒸馏水, 以确保样品不会被烧干和碳酸盐充分除去, 使颗粒松散. 约 $20 \mathrm{~min}$ 后, 停止加热, 并 使每个烧杯都注满蒸馏水, 静置一夜. 第二天用小管吸出烧杯中的水, 加入浓度为 $3.6 \%$ 的分散剂(六偏磷 酸钠), 然后放进超声波震荡仪, 震荡 10min 后即可用 Malvern Mastersizer 2000 激光粒度仪进行测试, 全 部粒度样品的测试工作在兰州大学西部环境教育部重点实验室完成. 粒度参数计算采用以下公式 ${ }^{[22]}$ :

$$
\begin{array}{ll}
X_{\phi}=\sum\left(f_{i} m_{i}\right) / \sum f_{i} & \delta_{\phi}=\left[\sum f_{i}\left(m_{i}-X_{\phi}\right)^{2} / \sum f_{i}\right]^{1 / 2} \\
S K_{\phi}=\sum f_{i}\left(m_{i}-X_{\phi}\right)^{3} / \sum f_{i} \delta_{\phi}{ }^{3} & K_{G}=\sum f_{i}\left(m_{i}-X_{\phi}\right)^{4} / \sum f_{i} \delta_{\phi}{ }^{4}
\end{array}
$$

其中, $X_{\Phi}$ 代表平均粒径, $\delta_{\Phi}$ 为分选系数, $S K_{\Phi}$ 为偏度值, $K_{G}$ 为峰态值, $f_{i}$ 为每个粒级权重, $m_{i}$ 为各粒级平均粒 径, $\sum f_{i}$ 等于 100 .

\section{3 粒度测试结果分析}

根据粒度测试结果，绘制临夏盆地研究剖面沉积物各阶段粒径类型分布曲线(图 2), 众数分布(图 3)和 粒径在区间 10-40m 以及 $>63 \mu \mathrm{m}$ 颗粒的质量累计比率曲线(图 4). 由于考虑的只是特定粒径区间的粒度参 
数变化, 故而用篎析法和激光粒度仪法测试的样品粒度参数变化能较容易的结合起来, 下面对以上各粒 度实验结果逐一分析.
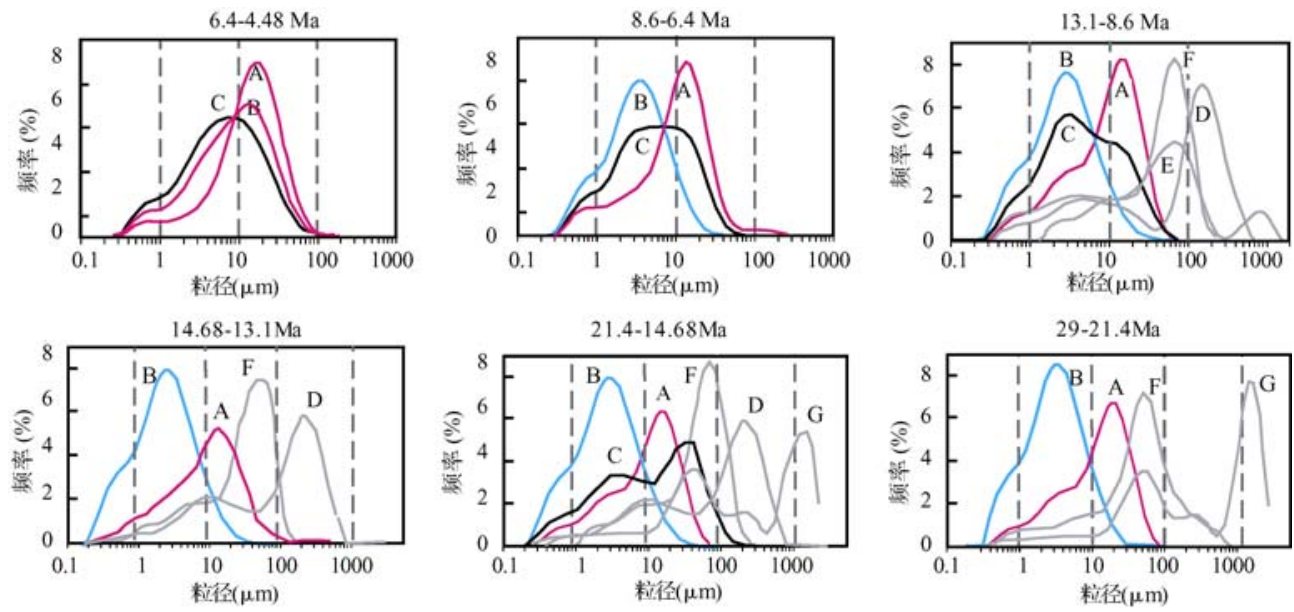

图 2 毛沟剖面粒径分布类型变化

Fig.2 The distribution types of grain size in Linxia Basin
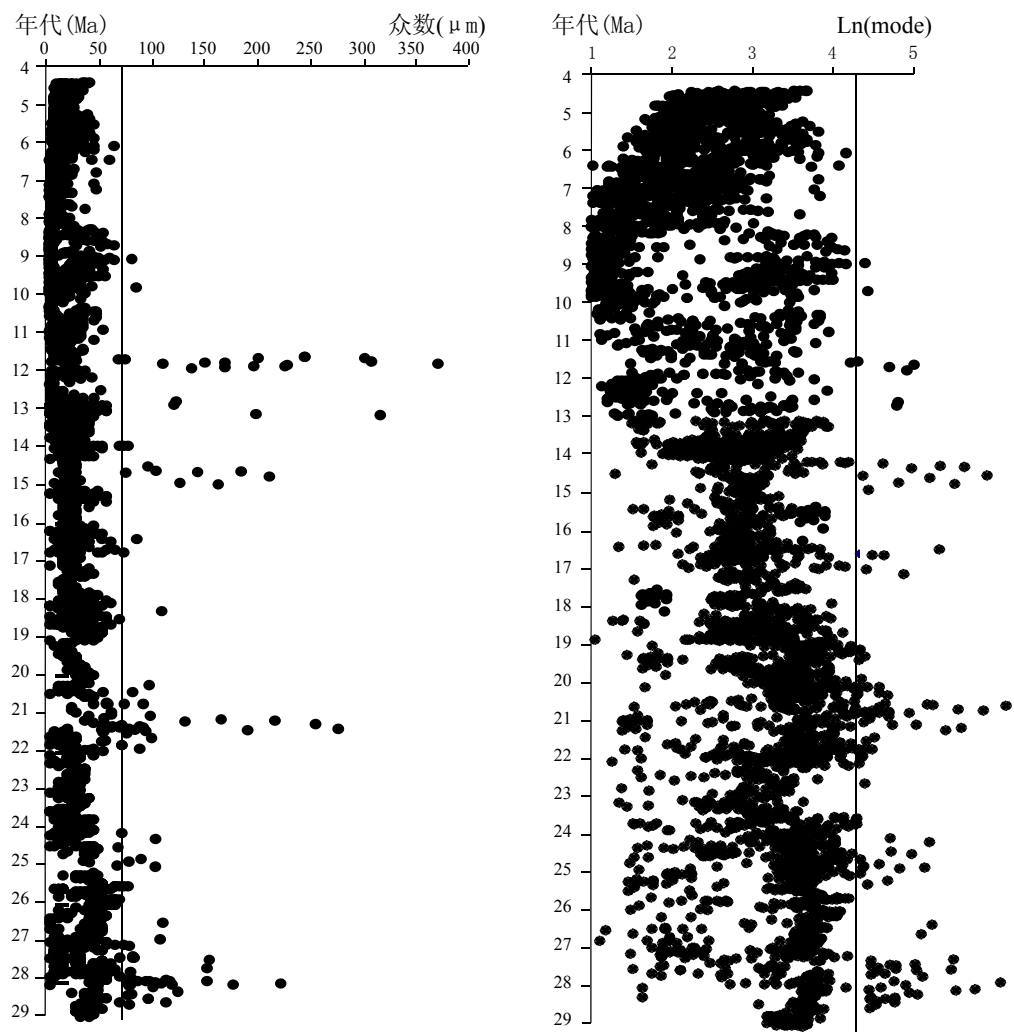

图 3 毛沟剖面众数粒径一年代分布

Fig.3 Variation of the mode of sediment grain sizes in the Maogou Section since $29 \mathrm{Ma}$ 


\section{1 粒径类型分布曲线}

粒径类型分布曲线(图 2)显示: 整个研究时段沉积物粒径分布总体可以归结为 7 种类型(A-G). A、B 和 $\mathrm{C}$ 三种类型的众数粒径都小于 $70 \mu \mathrm{m}$, 其粒径分布基本集中小于 $40 \mu \mathrm{m}$ 的细粒部分，粗粒组分含量极少.D、 E、 $F$ 和 $G$ 四种类型的众数粒径都大于 $70 \mu \mathrm{m}$ ，其中， D 与 $G$ 两种类型基本呈双峰分布，且粒径主要分布在 $1000 \mu \mathrm{m}$ 左右的粗端部分, 这两种类型集中分布于粒径组成较粗河流相沉积物中; $\mathrm{E}$ 和 $\mathrm{F}$ 两种类型粒径分布 主要集中于 50- $100 \mu \mathrm{m}$ 之间, 主要出现在湖相沉积物中. A 类型在整个研究时段中一直存在; 类型 B 在三角 洲相沉积中少见，而在 11-6.4Ma 分布普遍，到 6.4Ma 以后消失了; $\mathrm{C}$ 类型在 $13.1 \mathrm{Ma}$ 以后一直存在; $\mathrm{D} 、 \mathrm{E}$ 和 $\mathrm{F}$ 三种类型仅在 $8.6 \mathrm{Ma}$ 以前出现; 类型 $\mathrm{G}$ 仅在 $14.68 \mathrm{Ma}$ 以前出现. 总的来说, 粒径类型分布沿剖面向上逐 步走向单一化, 最后到剖面顶部的何王家组只存在 $\mathrm{A}$ 和 $\mathrm{C}$ 俩种类型. 这种单一化不仅在粒度的分布类型 上表现明显，在单个类型的曲线变化上也有体现，类型 $\mathrm{A}$ 在粒径组成上逐渐变得单一，类型 $\mathrm{C}$ 中代表砂 岩组分的双峰逐渐走向重合. 当然, 在整个剖面粒径类型分布曲线中, 还存在其他少数几种类型, 但其 变化特征和上述几种类型大体相似，这里可以近似的认为他们包含在上述类型之中.

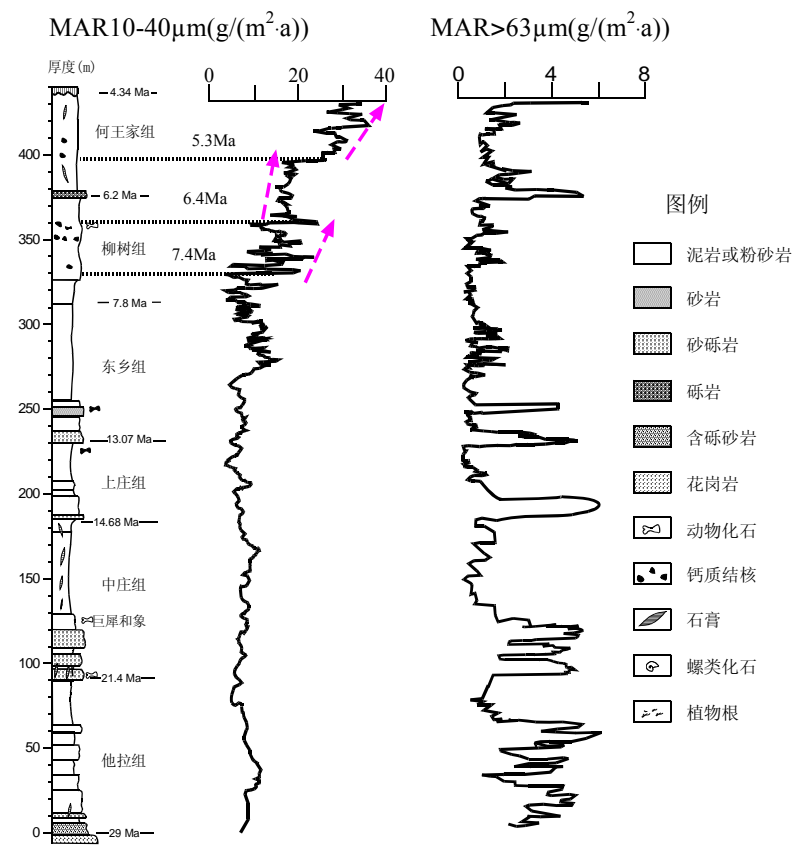

图 4 临夏盆地沉积物 $10-40 \mu \mathrm{m}$ 与 $>63 \mu \mathrm{m}$ 颗粒质量累计比率随地层变化曲线

Fig.4 Depth function of the MAR curves of $10-40 \mu \mathrm{m}$ and $>63 \mu \mathrm{m}$ particles of sediments in Linxia Basin

\section{2 众数分布}

众数是指最大百分含量所对应的粒级值, 它不受数据资料中的极端值影响, 其变化可以指示剖面粒 径变化的主要趋势. 通过研究剖面沉积物粒度众数分布(图 3)可以得出如下结论:

(1)由于 $8.6 \mathrm{Ma}$ 以来粒度分布类型只存在 $\mathrm{A} 、 \mathrm{~B}$ 和 $\mathrm{C}$ 三种类型，而剖面粒度众数-年龄图清楚的显示, $8.6 \mathrm{Ma}$ 以来剖面沉积物粒径的众数均小于 $70 \mu \mathrm{m}$ ，由此推知 $\mathrm{A} 、 \mathrm{~B}$ 和 $\mathrm{C}$ 三种类型的众数均小于 $70 \mu \mathrm{m}$, 而 $\mathrm{D}$ 、 $\mathrm{E} 、 \mathrm{~F}$ 和 $\mathrm{G}$ 四种类型的众数均大于 $70 \mu \mathrm{m}$ ，这点从粒径频率分布图上也可以大致看出来.

(2)小于 $70 \mu \mathrm{m}$ 的众数在整个剖面一直占优势地位，这意味着 $\mathrm{A} 、 \mathrm{~B}$ 和 $\mathrm{C}$ 三种或者其中某一两种类型 在整个研究剖面一直处于优势地位.

(3)从剖面粒径众数对数转化图可以清楚的看出：8.6Ma 以来剖面沉积物粒径的众数逐渐增大，这意味 着剖面沉积物众数粒径组成逐渐变粗. 


\section{3 质量累计比率曲线}

粒径的质量累计比率是样品的体积密度和线性累计率的乘积, 线性累计率是单位时间内沉积的样品 层厚度，沉积时间由古地磁极性年龄线性推导得出，中国黄土高原的黄土体积密度变化于 $1.28-1.7 \mathrm{~g} / \mathrm{cm}^{3}$ 之间 ${ }^{[23]}$, 这里取 $1.48 \mathrm{~g} / \mathrm{cm}^{3}$ 来代替临夏盆地粒径为 $10-40 \mu \mathrm{m}$ 区间的风成成分的体积密度, 极端值误差不 超过 $15 \%$. 对于 $>63 \mu \mathrm{m}$ 的粒径, 由于我们研究的只是各粒径区间质量累计比率的一个总的变化趋势, 密 度值的差异并不影响对整个研究时段各种粒径范围变化趋势的研究, 故对体积密度我们仍然取上述值来 进行计算. 质量累计比率图同粒径百分比图相比具有更明显的优势: 质量累计比率图能消除在某一不确 定时段其他粒径类型变化所带来的影响, 例如, 如果在某一时段一直都有砂岩的加人, 那么砂岩沉积物 的增加将改变砂在整个沉积物中的百分比, 而对质量累计比率却没有多大影响.

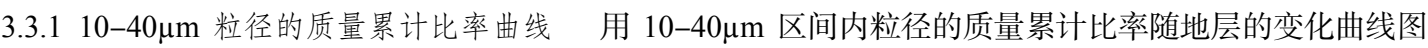

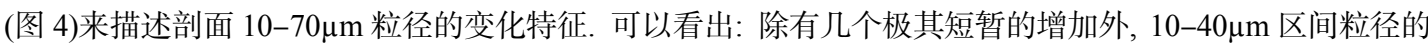
质量累计比率在整个 29-7.4Ma(0-437m) 阶段相对稳定, 没有长期变化; $7.4 \mathrm{Ma}$ (约 $331 \mathrm{~m}$ 左右)后该比率开始 发生变化: 7.4-6.4Ma(约 331-363m), 质量累计比率升降波动幅度较大, 但总体上呈缓慢的上升趋势,尤其是 峰值增加明显; 6.4-5.3Ma(约 363-398 m), 质量累计比率值较前有一个台阶式增加, 且增加以后保持相对稳 定或者稍有上升; 5.3-4.48Ma(约 398-437m)，质量累计比率呈现快速持续的上升过程.

3.3.2 $>63 \mu \mathrm{m}$ 粒径的质量累计比率曲线 分析 $>63 \mu \mathrm{m}$ 的砂粒径组分的质量累计比率曲线(图 4), 可以看 出, 除 29-25Ma(约 0-70m)、21.5-19Ma(约 90-120m)、14.7-13.9Ma(约 $186-200 \mathrm{~m}$ )、13.0Ma(约 $233 \mathrm{~m}) 、$ $11.5 \mathrm{Ma}($ 约 $250 \mathrm{~m}) 、 6.0 \mathrm{Ma}$ (约 $375 \mathrm{~m}$ ) 和 $9.8-8.7 \mathrm{Ma}$ (约 $275-305 \mathrm{~m}$ )这几个时期质量累计比率相对较高外, 29-4.48Ma 期间, $>63 \mu \mathrm{m}$ 粒径组分的质量累计比率保持相对稳定.

\section{4 结果与讨论}

为了揭示剖面沉积物粒度记录所反映的新生代以来的气候变化, 将粒度记录与深海氧同位素曲线相对 比(图 5), 并根据 10-40 $\mu \mathrm{m}$ 和 $>63 \mu \mathrm{m}$ 粒径的质量累计比率变化将整个研究时期的环境演化划分为三个阶段.

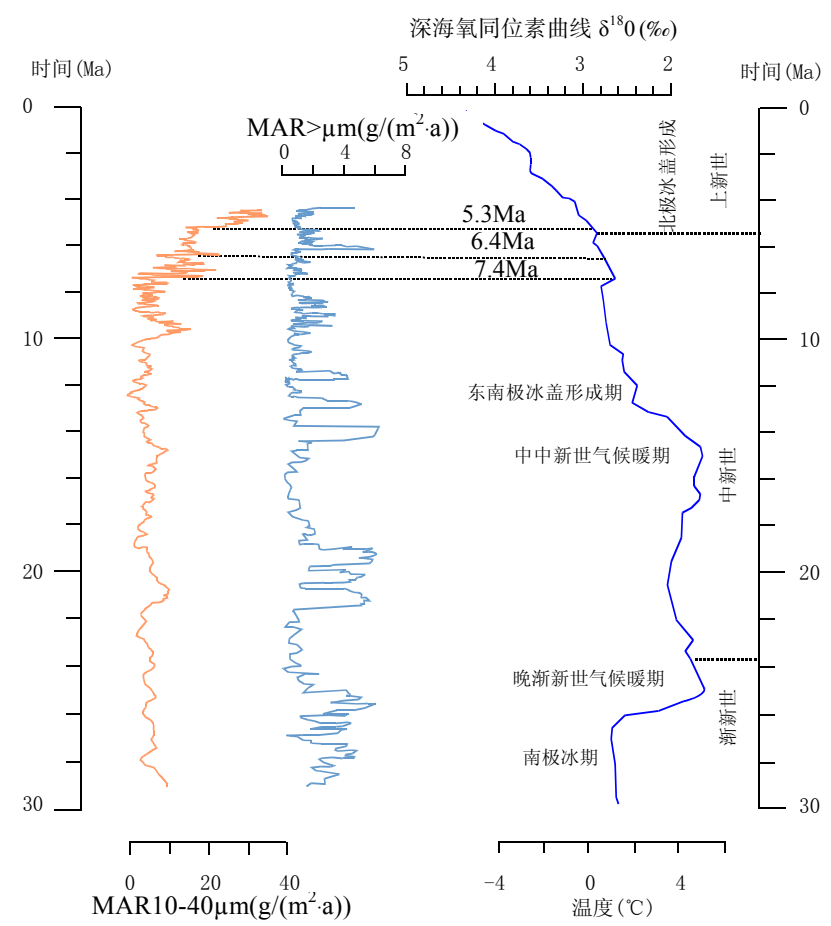

图 5 粒度记录与深海氧同位素变化曲线对比 ${ }^{[2]}$

Fig.5 Diagram contrasting grain size indexes with deep sea oxygen isotope 


\section{1 气候条件保持相对平稳阶段 29-7.4Ma}

图 4 或图 5 显示除 9.8-8.2Ma 短暂时段外, 10-40 $\mu \mathrm{m}$ 粒径的质量累计比率在 29-7.4 Ma 变化较相对 平稳，没有显著的气候环境事件发生，也没有表现出气候的长期变化. 临夏盆地中的沉积物大多在一个 浅水和氧化的封闭或者半封闭的湖相沉积背景下形成的, 这种环境使得剖面沉积物中 $>63 \mu \mathrm{m}$ 的砂粒组分 的质量累计比率在整个 29-4.48 Ma 时期同样保持相对稳定, 其间虽在 29-26Ma、21.5-19 Ma、14.7-13.9 $\mathrm{Ma} 、 13.0 \mathrm{Ma}$ 和 $11.5 \mathrm{Ma}$ 各短暂时段出现相对高值, 但它们正好对应了这些部位的相变化: 29-26 Ma 主要 为洪积扇前缘沉积, 21.5-19Ma 为大型辫状河流沉积, 13.0 Ma 和 11.5 Ma 属于河流相. 9.8-8.2 Ma 为滨湖相 沉积 ${ }^{[24]}$, 该时段 10-40 $\mu \mathrm{m}$ 与 $>63 \mu \mathrm{m}$ 的粒径质量累计比率出现短暂高值, 其原因可能是有河流沉积物输人 或者是此阶段湖泊水面波动较大引起的. 碳酸钲和氯离子研究表明 ${ }^{[15]}, 13.1-8 \mathrm{Ma}$ 间存在几个明显相对干 旱和湿润交替阶段，且 9.8-8.2 Ma 正是碳酸钙和氯离子含量由一较低值向 8-6 Ma 的极端高值过渡期，二 者含量波动较大; 孢粉组合中 ${ }^{[25]}$, 针、阔叶树在 9.8-8.2Ma 百分比含量波动也很明显; 这些指标共同揭示 出此阶段气候干湿变化较大; 宋春晖等 ${ }^{[24]}$ 根据对同一剖面色度指标分析，同样揭示了剖面在 13.07-8Ma 间气候干湿变化波动较大. 因此,气候干旱期, 湖泊水位下降, 湖面收缩, 沉积物距离湖岸较近, 粗颗粒 物质易于到达，从而使沉积的粗颗粒含量增加; 反之，气候湿润期，湖泊水位上升，湖面扩张，沉积物距 离湖岸远, 粗颗粒物质难以到达, 较深水的弱动力环境有利于细颗粒物质沉积. 这种气候干湿变化引起 湖泊水面变化可能是 9.8-8.2 Ma 间 10-40 $\mu \mathrm{m}$ 和 $>63 \mu \mathrm{m}$ 粒径组分的质量累计比率增加的原因. 但不管怎样, 各粒径组分的质量累计比率在这几个短暂时段内的增高, 并不影响整个研究时段沉积物各粒径指标保持 相对稳定的变化趋势.

将本阶段粒度指标与深海氧同位素变化曲线进行比较分析(图 5)可以看出，此阶段盆地沉积物各项 指标的变化与深海氧同位素的变化之间没有相关性, 30-9Ma 之间全球气候最显著的变化就是盛期南极 冰盖(33-26Ma)在 $26 \mathrm{Ma}$ 的急剧减小, 同时全球气温在此时的显著增加, 即所谓的晚渐新世温暖事件(Late Oligocene Warming $)^{[1-2]}$, 这个增温基本一直持续到中新世早、中期, 并在约 18-15Ma 达到最大, 称为中中 新世气候最温暖期或气候最适宜期(Mid-Miocene Climatic Optimum), 在约 14.5-13Ma, 随着东南极冰盖 的生成和扩张, 全球气温开始急剧下降(图 5), 在这些重大的气候环境事件时期, 我们的记录几乎没有什 么响应，粗颗粒在 29-26Ma、21.5-19Ma(大型辫状河流沉积)、14.7-13.9Ma、13.0Ma 和 $11.5 \mathrm{Ma}$ (河流相) 和 9.8-8.2 Ma(滨湖相沉积)增加, 理解为是盆地沉积物和沉积相对这些时期构造事件的响应 ${ }^{[26,18]}$ (这几个 阶段中, 为了作图的方便性, 把 $>63 \mu \mathrm{m}$ 的砂砾岩质量累计比率按一定的比率缩放, 这并不影响对整个曲 线图变化趋势的分析). 因此, 一个合理的解释应该是本区自 $29 \mathrm{Ma}$ 以来一直处于一种较干的状态, 因此 早先孢粉研究主要依据松(Pinaceae)和柏(Cupressaceae)增加所得出的临夏盆地中新世变得较湿润的结论, 这个湿润程度可能没有想象的那么大, 仍然是在相对较干的背景下的相对湿润. 从狍粉自身组成来看, 松和柏都是耐旱树种, 现今也主要分布在我国西北半湿润和半干旱地区.

\section{2 气候变化的过渡阶段(7.4-6.4Ma)和快速变化阶段(6.4-4.48Ma)}

10-40 $\mu \mathrm{m}$ 颗粒的质量累计率从 7.4Ma 开始呈现缓慢上升的趋势, 尤其是峰值的逐渐升高表现相当明 显，而 $>63 \mu \mathrm{m}$ 粗颗粒的质量累计比率曲线在 7.4-6.4Ma 间表现出相当的稳定，也即该阶段湖区环境没有 发生明显变化(图 4 或图 5). 因此, 推断湖泊沉积物粒度指标所发生的变化, 只能是由湖区外环境的变化 所引起的. 从 $6.4 \mathrm{Ma}$ 开始, 10-40 $\mu \mathrm{m}$ 颗粒的质量累计率发生了急剧的变化, 呈现出持续快速的上升趋势, 并且从 5.3 Ma 开始, 这种变化再次加快, 同样, $>63 \mu \mathrm{m}$ 粗颗粒的质量累计比率曲线在此期间仍然表现出相 当的稳定, 仅在 $6.1 \mathrm{Ma}$ 左右有一非常短暂的快速增加, 在剖面上, 这个粗颗粒快速增加正好对应这个时 期的一个呈透镜状分布的薄层含砾砂岩层，它代表了短暂的河流摆动沉积 ${ }^{[24]}$, 可能也与这个时期高原东 北部一次短暂的快速抬升事件有关 ${ }^{[16,18,27]}$. 因此, 这种加速的气候变化阶段仍然可能主要是流域外环境 变化因素造成.

\section{$57.4 \mathrm{Ma}$ 以来亚洲内陆的干旱化}

上述分析给出的 $7.4 \mathrm{Ma}$ 以来气候环境的持续变化和 $6.4 \mathrm{Ma}$ 与 $5.3 \mathrm{Ma}$ 的加速变化主要是由于流域以外 
的环境变化作用引起, 我们认为这个外部环境变化就是风成粉尘物质的加人.

不同成因的沉积物对应了不同粒度组成和特征. 前面粒度特征分析表明，临夏盆地不同时间段沉积 物的粒度组成变化, 从 $8.6 \mathrm{Ma}$ 开始, 除了短暂的河流摆动沉积物外, 众数全部小于 $70 \mu \mathrm{m}$, 集中在 $20 \mu \mathrm{m}$

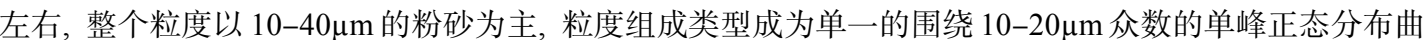
线, 类似于粉尘红粘土、黄土和现代粉尘的粒度组成 ${ }^{[28-29]}$ (图 6), 而在此之前, 围绕大众数的多种形态的 多峰分布曲线, 指示了水成作用下的多成因特点(图 2).
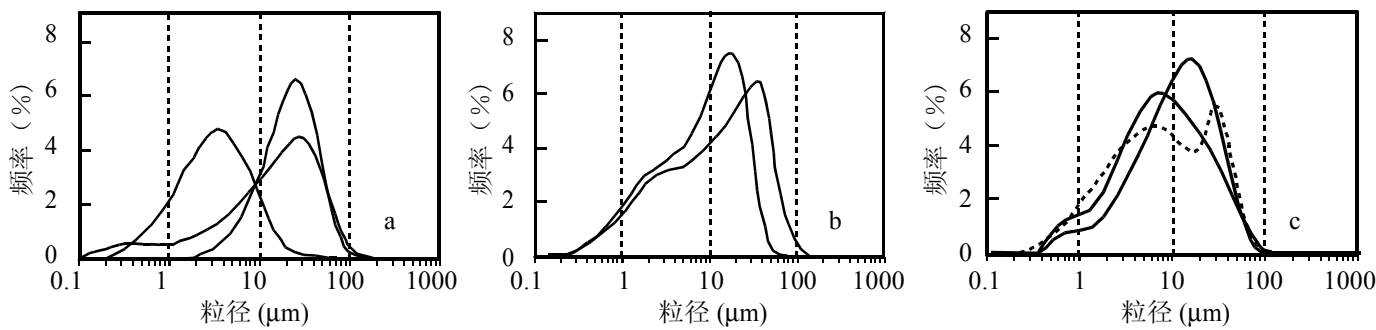

图 6 临近地区典型风成物质粒径分布

(a: 中国黄土高原现代粉尘; b: 黄土高原黄土; $\mathrm{c}$ 朝那红粘土(实线)和西峰红粘土(点线))

Fig.6 The grain size distribution curves of typical eolian dust near the Linxia Basin

(a: Modern Xifeng dust in the Loess Plateau; b: loess from the loess Plateau;

c: Chaona Red Clay and Xifeng Red Clay (dotted line))

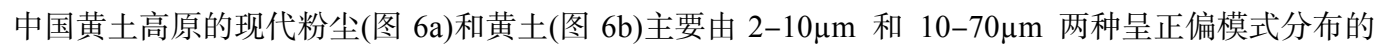
粒径成分组成 ${ }^{[30-31]}$. 西峰晚中新世红粘土粒径的双峰分布与黄土的粒径分布相似, 朝那红粘土的粒径分 布趋向于一个分布于 $2-70 \mu \mathrm{m}$ 较宽的单峰(图 6c $)^{[28-29]}$, 这种较宽的单峰特征可以理解为在与黄土沉积条

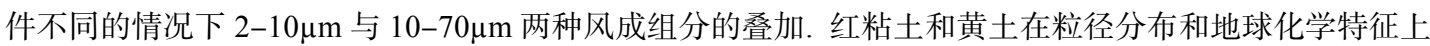
的相似性研究已揭示出红粘土是风成沉积物 ${ }^{[2]}$. 推测临夏盆地 7.4Ma 以来的颗粒组成如果主要是风成物 质, 其在粒径分布类型上应该与现代粉尘、黄土和红粘土相似. 基于这种理念, 将临夏盆地湖相沉积物中 $\mathrm{A}$ 与 $\mathrm{C}$ 两种粒径类型(图 2)分别与现代粉尘, 黄土和红粘土进行比较(图 6), 我们发现临夏盆地 $\mathrm{A}$ 粒径分 布类型与现代粉尘，黄土和朝那红粘土的粒径分布(图 6a,b,c一实线)十分相似, C 类型粒径分布与西峰红 粘土粒径分布(图 6c-虚线)非常接近.

临夏盆地沉积物不同时段平均粒径一分选系数及偏度一峰态散点图给出了进一步的证据: 沿剖面向 上, 散点分布范围逐渐减少, 到何王家组其在分布特征上和朝那红粘土平均粒径一分选系数及偏度一峰 态散点图已经非常相似(图 7). 稳定的封闭湖泊沉积环境条件下, 除非有外源物质(如粉尘)的加人, 否则, 剖面沉积物的粉砂粒径不会发生与其它组分含量变化无关的长期持续的增加或者减少. 临夏盆地湖泊沉 积物虽然其最终是水成的, 是流水搬运的, 但其与风成物质在特征上的相似性, 使我们认为盆地沉积物 粒度参数的持续增加可能是着风成粉尘物质从流域外不断的加入, 从而也很可能反映出我国西北 $29 \mathrm{Ma}$ 以来的干旱气候环境演化过程，即：29-7.4Ma 期间盆地气候可能一直处于半湿润的稳定状态，至 7.4Ma 左右, 我国西北明显持续变干, $6.4 \mathrm{Ma}$ 左右气候显著变干, 到 $5.3 \mathrm{Ma}$ 气候变干再次加快.

临夏盆地沉积物其它指标也都大致说明 $8 \mathrm{Ma}$ 左右我国西北开始变干. 例如: 通过野外观察, 我们注 意到剖面沉积物在颜色组成上, $8 \mathrm{Ma}$ 以前以紫红色和褐红色为主, 而到 $8 \mathrm{Ma}$ 以后转变为以褐黄色为主. 颜色的定量化研究进一步表明, 颜色指标 $\mathrm{L}^{*} 、 \mathrm{a}^{*} 、 \mathrm{~b}^{*}$ 在 13-8Ma 变幅和数值较大, 到 $8 \mathrm{Ma}$ 后变幅和数值 都突然减小, 至 $6.2 \mathrm{Ma}$ 后变幅进一步减小 ${ }^{[24]}$, 反映了剖面沉积物中各种矿物类型, 尤其是成色效果明显 的磁性矿物的相对含量发生了变化; 碳酸钙含量和氯离子浓度一直被视为封闭湖盆中对气候变化较为敏 感的两项指标，两者的高峰均代表了相对炎热时期, $8 \mathrm{Ma}$ 两者含量均有所增加，到 6.2 Ma 两者的含量分 别达到 $56.8 \%$ 和 $0.87 \%$, 均增加至研究时段的最高峰 ${ }^{[15]}$; 钕锶比、碳氧比也分别在 $8 \mathrm{Ma}$ 和 $6.2 \mathrm{Ma}$ 增加至 
最高峰 ${ }^{[16]}$, 这些地化指标的极端值变化均代表了气候相对干旱时期; 一般而言, 风砂作用的盛行代表了 干旱的气候环境，临夏盆地的风沙沉积研究表明成熟砂和风成砂含量在 $8 \mathrm{Ma}$ 和 $6.2 \mathrm{Ma}$ 明显增加 ${ }^{[33-34]}$; 孢 粉资料亦显示 13-8.5 Ma 为针阔混交林植被类型，代表相对暖湿环境，8.5Ma 之后狍粉组合中旱生、半旱 生含量大增, 转变为干草原环境, $6.2 \mathrm{Ma}$ 植被暂时变为针阔森林型, 之后草本含量再次增加 ${ }^{[27]}$.
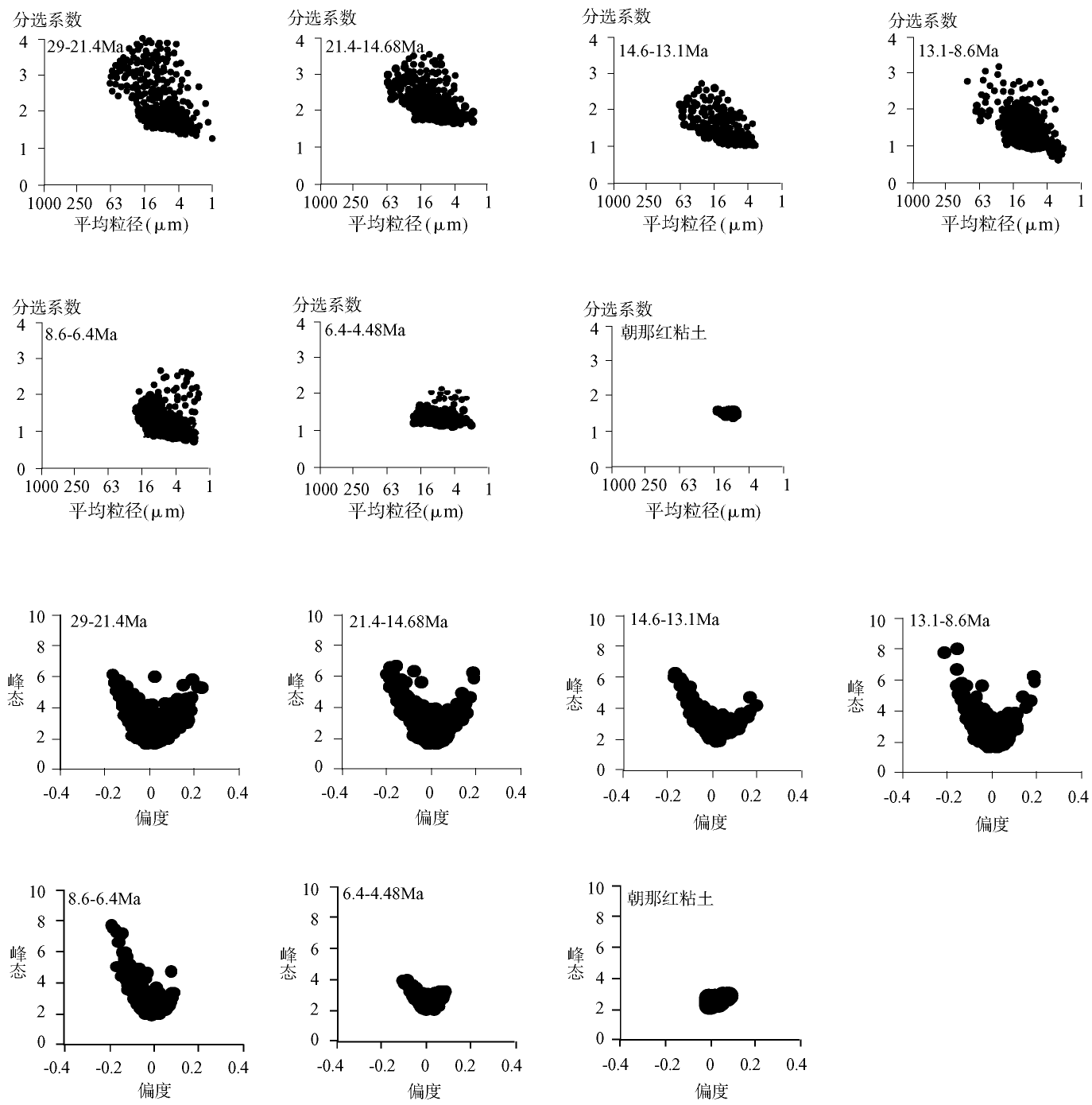

图 7 临夏盆地湖相沉积物与朝那红粘土粒度参数散点分布对比

Fig.7 Diagram contrasting frain size parameters of lade sediments in Linxia Basin with Chaona Red-clay

\section{6 亚洲内陆干旱化驱动机制探讨}

对比临夏剖面沉积物 10-40 $\mu \mathrm{m}$ 粒度质量累计比率曲线与深海氧同位素变化曲线 ${ }^{[2]}$ (图 5), 我们发现在 7.4-6.4Ma 之前, 粒度记录的环境变化与全球气候变化在宏观上没有任何联系, 但是 7.4-6.4Ma 以后, 其 所记录的我国西北干旱化进程显著加快与此时开始的全球氧同位素含量持续上升所揭示的全球变冷, 尤 其此时北极冰盖的形成和扩展基本同步同趋，因此，我们推测此时的西北干旱化与全球变冷，尤其北半 球高纬地区变冷很可能存在着某种相关性. 实际上, 对于晚新生代以来全球变冷与干旱化的关系, 前人 已经做了大量研究 ${ }^{[14,35-38]}$, 这些研究共同揭示了全球变冷对干旱化的重大影响. 
青藏高原的隆升是晚新生代以来的另一重要地质事件，隆升的高原通过改变地表下垫面条件和大气 环流状况而对亚洲内陆干旱化起着举足轻重的作用 ${ }^{[14,39]}$. 青藏高原东北部在 9-8Ma 左右开始发生的变形 隆升已经为众多的研究所证明，例如：祁连山北麓酒西盆地和拉脊山前贵德盆地在 $8 \mathrm{Ma}$ 开始发育生长地 层, 形成渐进不整合, 同时早先的湖相沉积逐步为扇三角洲沉积体系所代替, 沉积速率和砾石含量与直 径也逐步增大, 并从 6.4Ma 开始, 上述变化趋势明显加快 ${ }^{[27,40-41]}$; 祁连山和阿尔金山岩体热年代学分析表 明这些山系从约 9-7Ma 开始强烈冷却和抬升 ${ }^{[42-43]}$; 临夏盆地也从约 $8 \mathrm{Ma}$ 开始随着生长断层开始向盆地 内部扩展，断层前沿地层开始弯折，早先前陆盆地前渊的快速下沉开始变慢，转为上升，成为前陆盆地 的楔顶部位, 盆地开始快速旋转, 这个过程从 $6 \mathrm{Ma}$ 开始更加明显, 地层从 $38^{\circ}$ 倾角迅速渐变为 $18^{\circ}$, 盆地 快速顺时针旋转了 $10^{\circ[18]}$. 在青藏高原其它地区，这个时期的构造变形隆升也表现得非常明显，比如：拉 萨西北羊八井地堑形成于 $8 \mathrm{Ma}$ 前后，指示了高原南北向裂谷开始发育 ${ }^{[44]}$; 南亚西瓦立克群 Surai Khola 剖 面出现首层砾岩沉积 ${ }^{[45]}$; 喜马拉雅东构造结此时快速隆升 ${ }^{[46]}$.

综上所述, 我们推测 $7.4 \mathrm{Ma}$ 以来我国西北的干旱化之所以如此加速进行, 很可能是全球变冷和青藏 高原加速隆升双重驱动造成.

致 谢: 参加野外和实验工作的还有付开道、韩文霞、陈堂莹等，作者一并表示感谢.

\section{7 参考文献}

[1] Miller KG, Fairbanks RG, Mountain GS. Tertiary oxygen isotope synthesis, sea level history, and continental margin erosion. Paleoceanography, 1987, 2(1): 1-19.

[2] Zachos J, Pagani M, Sloan L. Trends, rhythms, and aberrations in global climate 65Ma to present. Science, 2001, 292: 686-693.

[3] Ruddiman WF, Kutzbach JE . Forcing of late Cenozoic Northern Hemisphere climate by plateau uplift in Southern Asia and the American West. J Geophys Res, 1989, 94: 18409-18427.

[4] Li Jijun. Uplift of Qinghai-Xizang(Tibet) Plateau and Global Change. Lanzhou: Lanzhou University Press, 1995: 38-39.

[5] 刘东生, 郑锦平, 郭正堂. 亚洲季风系统的起源和发展及其两极冰盖和区域构造运动的时代耦合性. 第四纪研究, 1998, (3): 194-204.

[6] An ZS, Kutzbach JE, Prell W. Evolution of Asian mosoons and phased uplift of the Himalaya-Tibetan plateau since Late Miocene times. Nature, 2001, 411: 62-66.

[7] Wang P, Clemens S, Beaufort L et al. Evolution and variability of the Asian monsoon system: state of the art and outstanding issues. Quat Sci Rev, 2005, 24: 595-629.

[8] Fennessy MJ , Kinter JL, Kirtman B et al. The effects of orography on middle latitude northern hemisphere dry climates. J Clim, 1992, 5: 1181-1201.

[9] DeMenocal PB, Rind D. Sensitivity of Asian and African climate to variation in seasonal insolation, glacial ice cover, sea surface temperature, and Asian orography. J Geol Res, 1993, 98: 7265-7287.

[10] Molnar P, England P, Martinod J. Mantle dynamics, uplift of the Tibetan Plateau, and the Indian monsoon. Reviews of Geophysics, 1993, 31: 357-396.

[11] Ramstein G, Fluteau F, Besse J. Effect of orogeny, plate motion and land-sea distribution on Eurasian climate change over the past 30 million years . Nature, 1997, 386: 788-795.

[12] Raymo ME, Ganley K, Carter S et al. Millennial-scale climate instability during the early Pleistocene epoch. Nature, 1998, 392: 699-702.

[13] Rea DK, Snoeckx H, Joseph LH. Late Cenozoic eolian deposition in the North Pacific: Asian drying, Tibetan uplift, and cooling of the northern hemisphere. Paleoceanography, 1998, 13(3): 215-224.

[14] 郭正堂, 彭淑贞, 郝青振等. 晚第三纪中国西北干旱化的发展及其与北极冰盖形成演化与青藏高原隆升的关系. 第四纪 研究, 1999, 19(6): 556-567.

[15] 李吉均, 方小敏, 朱俊杰等. 临夏盆地新生代地层古地磁年代与模式序列. 见: 青藏项目专家委员会编. 青藏高原形成演 化、环境变迁与生态系统研究(1994). 北京: 科学出版社, 1995: 41-53. 
[16] 方小敏, 李吉均, 朱俊杰等. 甘肃临夏盆地新生代地层绝对年代测定与划分. 科学通报, 1997, 42(14): 1457-1471.

[17] 李吉均, 方小敏, 潘保田等. 新生代晚期青藏高原强烈隆起及其对周边环境的影响.第四纪研究, 2001, 21(5): 381-391.

[18] Fang XM, Garzione C, Vander Voo R et al. Flexural subsidence by 29 Ma on the NE edge of Tibet from the magnetostratigraphy of Linxia Basin, China. Earth Planet Sci Lett , 2003, 210(3-4): 545-560.

[19] 李吉均, 方小敏, 马海洲等. 晚新生代黄河上游地貌演化与青藏高原隆起. 中国科学( D 辑), 1996, 26(4): 316-322.

[20] Li JJ, Fang XM, Vander Voo R et al. Late Cenozoic magnetostratigraphy (11-0 Ma) of the Dongshanding and Wangjiashan sections in the Longzhong Basin, western China. Geologie \& Mijnbouw, 1997, 76: 121-134.

[21] 甘肃省区调队. 1: 20 万中华人民共和国地质图说明书, 临夏幅. 北京：地质出版社, 1965.

[22] 成都地质学院陕北队. 沉积岩(物)粒度分析及其应用. 北京：地质出版社, 1976: 3154.

[23] 刘东生. 黄土的物质成分和结构. 北京: 科学出版社, 1966.

[24] 宋春晖, 白晋锋, 赵彦德等. 临夏盆地 13-4.4Ma 湖相沉积物颜色记录的气候变化探讨. 沉积学报, 2005, 23(3): 507-513.

[25] 马玉贞, 李吉均, 方小敏. 临夏地区 30.6-5.0Ma 红层狍粉植物群与气候演化记录. 科学通报, 1998, 43(3): 301-304.

[26] 李吉均, 方小敏. 青藏高原隆起与环境变化研究. 科学通报,1998, 43(15): 1569-1574.

[27] Fang XM, Yan MD, Vander Voo R et al. Late Cenozoic deformation and uplift of the NE Tibetan Plateau: evidence from high-resolution magnetostratigraphy of the Guide Basin, Qinghai Province, China. Geol Soc Am Bull, 2005, 117, 1208-1225.

[28] 宋友桂, 李吉均, 方小敏. 黄土高原最老红粘土的发现及其地质意义. 山地学报, 2001, 19(2): 104-108.

[29] 孙东怀, 鹿化显, David R 等. 中国黄土粒度的双峰分布及其古气候意义. 沉积学报, 2000, 18(3): 327-335.

[30] Sun D, Bloemendal J, Rea DK et al. Bimodal grain-size distribution of Chinese loess, and its palaeoclimatic implications. Catena, 2004, 55: 325-340.

[31] Sun D, Bloemendal J, Rea DK et al. Grain-size distribution function of polymodal sediments in hydraulic and aeolian environments, and numerical partitioning of the sedimentary components. Sediment Geol, 2002, 152: 263-277.

[32] Yang S, Ding Z. Comparison of particle size characteristics of the Tertiary 'red clay' and Pleistocene loess in the Chinese Loess Plateau: implications for origin and sources of the 'red clay'. Sedimentology, 2004, 51: 77-93.

[33] 王建力, 方小敏, 李吉均. 青藏高原东北 15Ma 以来的风沙沉积. 科学通报, 1999, 44(12): 1326-1331.

[34] 王建力, 方小敏. 临夏盆地晚中新世以来的风沙沉积及环境意义. 地理科学, 2000, 20(3): 259-263.

[35] 陈明扬. 中国风尘堆积与全球干旱化. 第四纪研究, 1991, 4: 361-371.

[36] 孙有斌, 周 杰, 安芷生. 晚新生代黄土高原风尘堆积与粉尘源区干旱化问题. 地学前缘, 2001, 8(1)77-81.

[37] 刘秀铭, 安芷生, 强小科等. 甘肃第三系红粘土磁学性质初步研究及古气候意义. 中国科学(D 辑), 2001, 31(3): 192-205.

[38] 王先彦, 鹿化显, 季峻峰等. 青藏高原东北缘中新世红色土状堆积序列的成因及其对亚洲干旱过程的指示. 中国科学(D 辑), 2006, 36(3): 261-272.

[39] 刘晓东, 李 力, 安芷生. 青藏高原隆升与欧亚内陆及北非的干旱化. 第四纪研究, 2001, (2): 114-122.

[40] 宋春晖, 方小敏, 高军平等. 青藏高原东北部贵德盆地新生代沉积演化与构造隆升. 沉积学报, 2001, 19 (4): 493-500.

[41] 方小敏, 赵志军, 李吉均等. 祁连山北缘老君庙背斜晚新生代磁性地层与高原北部隆升. 中国科学(D 辑), 2004, 34(2): 97-106.

[42] Jolivet M, Brunel M, Seward D et al. Mesozoic and Cenozoic tectonics of the northern edge of the Tibetan plateau: fission-track constraints. Tectonophysics, 2001, 343: 111-134.

[43] 万景林, 王 瑜, 李 齐等. 阿尔金山北段晚新生代山体抬升的裂变径迹证据. 矿物岩石地球化学通报, 2001，20(4): 222-224.

[44] Harrison TM, Copeland P, Kidd WS et al. Raising Tibet. Science, 1992, 255: 1663-1670.

[45] Johnson NM, Opdyke ND, Johnson GD et al. Magnetic polarity stratigraphy and ages of Siwalik Group rocks of the Potwar, Pakistan. Palaeogeography, Palaeoclimatology, Palaeoecology, 1982, 93: 27-40.

[46] 钟大春, 丁 林. 青藏高原的隆起过程及其机制探讨. 中国科学(D辑), 1996, 26(4): 289-295. 